\title{
Effect of personality traits on the oral health-related quality of life in patients with oral lichen planus undergoing treatment
}

\author{
Dvorak Gabriella ${ }^{1}$ (D) $\cdot$ Rappersberger Klemens ${ }^{2} \cdot$ Rausch-Fan Xiao-hui ${ }^{1} \cdot$ Bruckmann Corinna $^{1} \cdot$ Hofmann Eva $^{3}$
}

Received: 4 February 2020 / Accepted: 1 September 2020 / Published online: 14 September 2020

(C) The Author(s) 2020

\begin{abstract}
Objectives The aim of this study was to evaluate the relationship between personality traits and perceived treatment success in oral lichen planus.

Material and methods A total of 53 patients with diagnosed oral lichen planus were evaluated at the time of diagnosis and along the course of their treatment. The visual analogue scale (VAS) was used for evaluating pain and burning sensation, along with an evaluation of the oral health-related quality of life (OHIP) and the clinical severity. In order to determine the personality trait, the NEO-FFI questionnaire was applied. Data were assessed with the statistical software Stata by a multiple linear regression.

Results A significant relationship between the two personality traits: "conscientiousness" and "extraversion" and a perceived improvement in oral lichen planus could be observed. The higher the "conscientiousness," the better the perceived oral healthrelated quality of life. Furthermore, "extraversion" had a significant influence on the improvement in clinical severity index $(P<$ $0.05)$.

Conclusions Personality traits, especially conscientiousness and extraversion, have a significant impact on the perception of therapeutic intervention in oral lichen planus.

Clinical relevance As personalized patient management is gaining importance and psychosocial factors play a significant role in mucosal diseases, the patient's psychological profile should be considered in the oral lichen planus management.
\end{abstract}

Keywords OHIP $\cdot$ NE-OFFI $\cdot$ OLP $\cdot$ Mucosal disease $\cdot$ Therapeutic outcome $\cdot$ Therapy

\section{Introduction}

Oral lichen planus (OLP) is a chronic inflammatory mucocutaneous disease. Prevalent in around $2 \%$ of the general population, it mainly affects women between 30 and 60 years of age. This immune disease is clinically characterized by different types of lesions, like reticular, so-called Wickham Striae, atrophic, or erosive areas, which may alternate [1]. Patients with symptomatic OLP require intensive care, as the disease

Dvorak Gabriella

gabriella.dvorak@meduniwien.ac.at

1 Clinical Division of Conservative Dentistry and Periodontology, University Clinic of Dentistry, Medical University of Vienna, Sensengasse 2a, 1090 Vienna, Austria

2 Department of Dermatology and Venereology, Medical Institution Rudolfstiftung, Juchgasse 25, 1030 Vienna, Austria

3 Competence Center for Empirical Research Methods, WU Vienna University of Economics and Business, Vienna, Austria may limit the perceived quality of daily life [2]. Specifically, pain stemming from erosive lesions may considerably impair food intake and oral hygiene accompanied by a high incidence of psychological problems. As of today, no curative treatment exists. Therapy focuses on the mitigation of symptoms, through drugs that counter inflammation and the underlying immune disorder. This symptomatic treatment may have side effects, like fungal infections or local irritations equally affecting oral health-related quality of life [3-5]. The uncertainty caused by OLP, as a potentially malignant disorder where the absence of available treatments to prevent such transformation [6], may stress the patients and affect their well-being [7].

OLP is assumed to be an autoimmune disease, yet the exact etiology is unknown. Psychological factors could play an important role as emotional stress is likely to be an associated risk factor. Furthermore, the burdens of chronic disease and persisting pain patients suffering from OLP are faced with require copying strategies. Personality traits influence behavior, compliance, and the perceived health-related quality of life, in mucosal diseases as elsewhere [8,9]. Whether 
therapeutic success in the treatment of mucosal disease is associated with personality traits remains unproven so far. In prosthetic and orthodontic rehabilitation, the psychological profile should be considered in formulating the treatment plan since the patient's satisfaction and acceptance are affected by personality traits [10-13].

The consequences of this condition on daily life, coping with the disease and quality of life, are all reflected by the Oral Health Impact Profile (OHIP). Also, the responsiveness of OHIP scores under therapy has been evaluated [14-16].

Clinicians should consider that psychological traits might play a relevant role in establishing individual limits of quality of life for specific treatments. Some measurable personality traits seem to have a considerable impact on individual satisfaction with therapy [17].

Since great importance is currently given to subjective outcome parameters, this study ought to provide additional data augmenting the possible contribution to clinical intervention.

We hypothesize that some personality traits are associated with higher scores of oral health-related quality of life in patients with OLP undergoing treatment.

\section{Material and methods}

This was an observational cohort study carried out at the University Clinic of Dentistry of Vienna, Austria. Ethical approval was obtained from the Ethics Committee of the Medical University of Vienna. All patients gave written consent for their participation. Patients were eligible, if their diagnosis of oral lichen planus (OLP) was confirmed by histopathology and direct immunofluorescence assay; any removable dentures were correctly fitting; minimum age was 18 years; no nicotine abuse was reported. Patients were excluded with a malignant transformation, severe dysplasia in histopathology, carcinoma in situ, severe vitamin deficiency, pregnancy, age below 18 years, lactation period, nicotine abuse, the presence of asymptomatic OLP, or oral mucositis of other origins (e.g., drug intake).

\section{Patient recruitment}

Patients with OLP were recruited at the outpatient clinic for mucosal diseases of the Division of Oral Surgery between October 2015 and August 2016. The diagnosis of OLP was made according to the clinical appearance and further confirmed by histopathology and direct immunofluorescence (IFT) analysis. All the tissue samples were taken by one specially trained surgeon (GD) and a specialist (KR) in immune dermatology and mucosal histopathology performed these analyses. The type of treatment (hyaluronic acid (Gengigel ${ }^{\circledR}$ ), topical triamcinolon (Volon $\left.{ }^{\circledR} \mathrm{A}\right)$, tacrolimus, cyclosporin, photodynamic therapy (PDT), systemic glucocorticoids or deproteinized hemodialysate of dairy calves (Solcoseryl ${ }^{\circledR}$ ointment), the time between appointments, the clinical severity of OLP, and the subjective outcome parameters of oral health-related quality of life and pain intensity were assessed as well as the personality traits by questionnaires. The type of treatment was chosen individually depending on the patient's symptoms in accordance with the treating dermatologist. In cases where the first-line treatment was not effective and patients came for a second opinion, calcineurin inhibitors were prescribed by a dermatologist (KR). Some of the patients suffering from lichen ruber planus of the skin or in other mucosal locations received systemic glucocorticoids. In mild cases or when patients refused immunosuppressant therapy, hyaluronic acid or hemodialysate was prescribed. All treatment options were discussed with the patient and the treating dermatologist, if available. Patients were recalled according to the clinical presentation every 3-6 months (90-200 days). In cases of subjective worsening, patients had the possibility to seek for an earlier appointment.

\section{Outcome parameters}

\section{Clinical severity index (Table 1) [18]}

The clinical presentation and the therapeutic improvement of clinical signs may be assessed by a clinical criteria score. The Thongprasom score is such a clinical severity index evaluating disease intensity in many OLP studies [18]. The CSI was assessed at each appointment.

0 , no lesion/normal mucosa; 1 , mild striae/no erythema; 2 , white striae with atrophic area $<1 \mathrm{~cm}^{2} ; 3$, white striae with atrophic area $>1 \mathrm{~cm}^{2} ; 4$, white striae with erosion $<1 \mathrm{~cm}^{2} ; 5$, white striae with erosion $>1 \mathrm{~cm}^{2}$.

\section{The visual analogue scale (Table 1)}

Subjective pain intensity evaluation is widely performed by a visual analogue scale (VAS) [19]. A customized absolute numeric scale ruler where patients rated their pain between 0 and $100 \mathrm{~mm}$ with a slider was used at each appointment. Scores of 0 imply "no pain," while 100 means the "worst pain imaginable." A recommendation for interpretation of the ratings suggest 0 to $4 \mathrm{~mm}$ to be read as no pain, 5 to $44 \mathrm{~mm}$ as mild pain, 45 to $74 \mathrm{~mm}$ as moderate pain, and 75 to $100 \mathrm{~mm}$ as severe pain. With this subjective evaluation method, it is possible to compare pain levels at every visit and to note score changes over time [20].

\section{Oral Health Impact Profile (Table 2)}

The OHIP is a cross-culturally adapted oral health-specific outcome measure recognized as an instrument suitable for the assessment of the oral health-related quality of life in 
Table 1 Baseline characteristics of patients

\begin{tabular}{|c|c|c|c|c|c|c|}
\hline Number & Age & Gender & Days between first and last visit & OHIP & VAS & CSI \\
\hline 1 & 58 & F & 1169 & 6 & 0 & 3 \\
\hline 2 & 79 & F & 70 & 11 & 1.1 & 4 \\
\hline 3 & 71 & $\mathrm{~F}$ & 646 & 12 & 10 & 3 \\
\hline 4 & 69 & M & 22 & 13 & 1 & 3 \\
\hline 5 & 70 & $\mathrm{~F}$ & 850 & 13 & 0 & 3 \\
\hline 6 & 58 & F & 1713 & 14 & 2.5 & 4 \\
\hline 7 & 79 & $\mathrm{~F}$ & 42 & 14 & 0 & 1 \\
\hline 8 & 31 & M & 511 & 18 & 2.5 & 1 \\
\hline 9 & 68 & $\mathrm{~F}$ & 581 & 21 & 0 & 1 \\
\hline 10 & 77 & M & 924 & 22 & 7.5 & 3 \\
\hline 11 & 54 & $\mathrm{~F}$ & 28 & 25 & 5 & 3 \\
\hline 12 & 60 & F & 14 & 28 & 3 & 4 \\
\hline 13 & 45 & F & 840 & 28 & 4.5 & 2 \\
\hline 14 & 55 & $\mathrm{~F}$ & 532 & 29 & 7.5 & 4 \\
\hline 15 & 33 & M & 560 & 29 & 2.9 & 2 \\
\hline 16 & 57 & $\mathrm{~F}$ & 525 & 34 & 6.7 & 4 \\
\hline 17 & 47 & F & 28 & 36 & 7.3 & 4 \\
\hline 18 & 61 & F & 280 & 36 & 0 & NA \\
\hline 19 & 60 & F & 504 & 38 & 0 & 1 \\
\hline 20 & 59 & F & 842 & 39 & 0 & 4 \\
\hline 21 & 47 & F & 21 & 43 & 0 & NA \\
\hline 22 & 64 & F & 91 & 45 & 5.2 & 2 \\
\hline 23 & 68 & F & 357 & 46 & 4.5 & 3 \\
\hline 24 & 47 & $\mathrm{~F}$ & 203 & 46 & 5.7 & 2 \\
\hline 25 & 74 & M & 525 & 50 & 7.6 & 4 \\
\hline 26 & 58 & $\mathrm{~F}$ & 1011 & 51 & 0 & 2 \\
\hline 27 & 49 & F & 693 & 51 & 2.5 & 1 \\
\hline 28 & 59 & F & 945 & 52 & 2.8 & 1 \\
\hline 29 & 49 & F & 540 & 57 & 3.2 & 1 \\
\hline 30 & 54 & F & 36 & 59 & 6.7 & 5 \\
\hline 31 & 74 & $\mathrm{~F}$ & 343 & 59 & 5 & 2 \\
\hline 32 & 49 & F & 189 & 61 & 0 & 2 \\
\hline 33 & 64 & F & 343 & 61 & 1.7 & 1 \\
\hline 34 & 43 & F & 476 & 61 & 0 & 1 \\
\hline 35 & 56 & F & 189 & 62 & 3.7 & 1 \\
\hline 36 & 24 & F & 84 & 65 & 8 & 1 \\
\hline 37 & 37 & $\mathrm{~F}$ & 252 & 67 & 0 & 2 \\
\hline 38 & 50 & F & 140 & 69 & 1.4 & 4 \\
\hline 39 & 21 & F & 217 & 70 & 5.5 & NA \\
\hline 40 & 54 & F & 210 & 71 & 3 & 1 \\
\hline 41 & 36 & F & 70 & 72 & 2.4 & 1 \\
\hline 42 & 72 & F & 98 & 74 & NA & 1 \\
\hline 43 & 69 & F & 106 & 75 & 5.2 & 4 \\
\hline 44 & 40 & F & 367 & 75 & 6.7 & 2 \\
\hline 45 & 42 & F & 458 & 81 & 3.1 & 2 \\
\hline 46 & 61 & F & 289 & 82 & 9.2 & 4 \\
\hline 47 & 74 & F & 140 & 82 & 7 & 4 \\
\hline 48 & 67 & F & 401 & 82 & 8 & 4 \\
\hline 49 & 71 & $\mathrm{~F}$ & 402 & 88 & 0 & NA \\
\hline 50 & 56 & $\mathrm{M}$ & 168 & 90 & 2.5 & 3 \\
\hline 51 & 60 & $\mathrm{~F}$ & 128 & 105 & 1.5 & 2 \\
\hline 52 & 58 & $\mathrm{~F}$ & 42 & 126 & 6.9 & 4 \\
\hline 53 & 53 & $\mathrm{M}$ & 152 & 151 & 3.4 & 3 \\
\hline
\end{tabular}

cross-sectional as well as longitudinal studies. The Oral Health Impact Profile questionnaire German version (OHIP$\mathrm{G})$ is an oral health-related quality of life instrument containing 53 questions concerning the previous 4 weeks of the patients' life. Answers to the 53 items of the OHIP-G are given on a Likert-type five-point scale ( 0 , never; 1 , hardly ever; 2, occasionally; 3 , fairly often; and 4, very often). In this analysis, the total summary OHIP-G score was utilized, 
Table 2 OHIP mean of the differences in the summary score, subscale score, and subdimension score changes between the first and last visit

\begin{tabular}{lll}
\hline Scale & Mean & Standard deviation \\
\hline OHIP-G & -0.2 & 0.5 \\
Functional limitation & -0.1 & 0.5 \\
Social disability & -0.1 & 0.5 \\
Handicap & -0.0 & 0.5 \\
Psychological disability & -0.3 & 0.6 \\
Physical disability & -0.2 & 0.5 \\
Psychological discomfort & -0.6 & 0.9 \\
Physical pain & -0.4 & 0.9 \\
DT & -0.1 & 0.6 \\
Oral function & -0.0 & 0.8 \\
Psychosocial impact & -0.2 & 0.6 \\
Orofacial pain & -0.5 & 1 \\
Appearance & -0.6 & 0.9 \\
\hline
\end{tabular}

calculated by summing the score of the answers to each question. Higher scores indicated the lower oral health-related quality of life. Summing the responses to subsets of items created subscale scores. OHIP-49 is divided into seven different parts. The possible score range for each of these is as follows: "functional limitation" (9 items) - from 0 to 36; "physical pain" (9 items) - from 0 to 36; "psychological discomfort" (5 items) - from 0 to 20 ; "physical disability" (9 items) - from 0 to 36; "psychological disability" (6 items) from 0 to 24; "social disability" (5 items) - from 0 to 20 ; "handicap" (6 items) - from 0 to 24; and finally "overall OHIP score" (49 items)—from 0 to 196. The German version has additional questions "DT" (4 items)-from 0 to 16 . Four dimensions (psychosocial impact, orofacial pain, oral functions, and appearance) served as principal components of oral health-related quality of life. The dimensions were calculated according to 21 stable rotational components as described previously.

The OHIP-G was assessed at each appointment.

\section{Neuroticism Extraversion Openness Five Factors Inventory}

This is an instrument to determine personality traits containing 60 questions. It analyzes five main behavior domains (neuroticism, extraversion, openness, agreeableness, and conscientiousness). Each of these domains is examined through 12 questions to be answered by one of the following Likerttype answers: "strong disagreement," 0 ; "disagreement," 1 ; "neutral," 2; "agreement," 3; or "strong agreement," 4.

Data processing and scoring procedures were performed using appropriate software provided with the instrument forms. Scores were calculated by specific algorithms based on the population characteristics (country, region). The average ratings for each domain in NEO-FFI-R were related to OHIP scores to verify the influence of psychological profiles.

\section{Statistical analysis}

For a medium effect size of $f^{2}=0.15$, statistical power of 0.85 , 17 predictor variables (sex, age, denture, missing teeth, CSI, 7 types of treatment, neuroticism, extraversion, openness, agreeableness, conscientiousness), and a probability level $P$ $=0.05$ at least 51 patients needed to be included for the multiple regression analyses. A multiple repeated measure regression (repeated over one to four treatment points per patient) was used to establish a predictive model on oral health-related qualitative life with oral lichen planus.

The repeated measure regression was performed with Stata statistical software package version 15 (Stata Corp LCC). Statistical values were considered significant when $P<0.05$ and highly significant when $P<0.001$.

\section{Results}

\section{Collective}

The study comprised a total of 53 patients, 46 women $(86.8 \%)$, and 7 men (13.2\%), distributed in following age categories: $21-35$ years of age 6 patients, $36-50$ years of age 12 patients, $51-65$ years of age 19 patients, $66-80$ years of age 16 patients. The mean age was $56.5 \pm 13.7$ years (min. $21-$ max. 79). The characteristics of the collective are presented in Table 1.

No removable denture was used by $79.2 \%(n=42), 18.9 \%$ $(n=10)$ were wearing a partial denture, and $1.9 \%$ had a complete denture $(n=1)$. The mean number of missing teeth was $5.3 \pm 5.5$ teeth, $18.9 \%(n=10)$ had no missing teeth, and 3.8\% had 20 missing teeth $(n=2)$. The mean time between the first visit and the last visit was $384 \pm 351$ days (min. 14-max. 1713 days). The mean time between the first and second visit was $241 \pm 220$ days (min. 14-max. 945 days). Eighteen patients came for a third visit after a mean period of $269 \pm 219$ days between the third and second visit (min. 14-max 959). Whereas 7 patients came for a fourth visit after a mean period of $392 \pm 413$ days between third and fourth visit (min. 91max. 1234). Eleven patients came before the recommended recall period and 32 after (90-200 days).

The difference between the last and first appointment was as follows:

The mean VAS improved by $-15 \pm 29 \mathrm{~mm}$, men showing significantly more improvement $(\mathrm{t}-2.5, P=0.02)$.

The mean clinical severity index (CSI) improved by $-1.2 \pm$ 1.2 under therapy. CSI improved significantly by the 
following factors: age, the number of missing teeth and the personality trait "extraversion."

In summary for all four appointments, CSI 0 was counted 6 times: CSI 1, 37 counts; CSI 2, 33 counts; CSI 3, 21 counts; CSI 4, 19 counts; CSI 5, 1 count. At the last visit, CSI 4 and 5 were not present while found in 15 patients at the baseline visit (Table 3)

Oral health-related quality of life, assessed by the mean OHIP summary score, improved with the elapsed time in between the visits (t-2.1, $P=0.04$ ) (Tables 2 and 3 ), when hyaluronic acid was used for treatment and the personality trait "conscientiousness" was pronounced. There was a worsening with topical triamcinolone use, with higher CSI scores (Tables 4 and 5).

Considering the different treatment options, $86.8 \%(n=46)$ of the patients were using hyaluronic acid (Gengigel $($ ) for a mean of $313 \pm 350$ days three times a day, $52.8 \%(n=28)$ topical triamcinolone for a mean of $162 \pm 321$ days three times a day, $7.5 \%(n=7)$ topical tacrolimus for a mean of $21 \pm 88$ days twice a day, $5.7 \%(n=3)$ systemic glucocorticoids for a mean of $18 \pm 127$ days, $22.6 \%(n=12)$ Solcoseryl dental adhaesive ${ }^{\circledR}$ several times a day for a mean of $69 \pm 198$ days, $3.8 \%(n=2)$ cyclosporine mouth rinse $(200 \mathrm{mg} / \mathrm{twice}$ daily for five minutes) for $19 \pm 115$ days, and $3.8 \%$ photodynamic therapy with 5-aminolevulinic acid once a day for $2 \pm 11$ days.

The NEO-FFI domains "neuroticism" showed a mean of $19.62 \pm 5.97$, "extraversion" $27.32 \pm 6.21$, “openness" 28.65 \pm 4.9 , "agreeableness" $33.75 \pm 4.96$, and "conscientiousness" $34.58 \pm 5.69$.

Table 3 Different OHIP summary scores (OHIP-G for the German version with 53 questions, OHIP 49 scores, and OHIP 14), subscale scores, and subdimension scores

\begin{tabular}{llllll}
\hline & 1st & 2nd & 3rd & 4th & Mean \\
\hline OHIP-G & 52.7 & 42.9 & 26.2 & 42 & 45.4 \\
OHIP 49 & 49.7 & 40.0 & 24.7 & 39.8 & 42.7 \\
OHIP 14 & 13.8 & 11.8 & 7.1 & 13.2 & 12.2 \\
Functional limitation & 8.6 & 8.7 & 5.4 & 7.7 & 8.3 \\
Social disability & 3.7 & 3.9 & 2.6 & 3.7 & 3.7 \\
Handicap & 4.3 & 4.1 & 2.0 & 7.2 & 4.2 \\
Psychological discomfort & 8.9 & 6.3 & 4.5 & 5.0 & 7.33 \\
Psychological disability & 6.6 & 5.2 & 2.7 & 9.7 & 5.7 \\
Physical disability & 7.8 & 7.0 & 4.4 & 9.2 & 7.2 \\
Physical pain & 14.1 & 11.3 & 9.2 & 9.8 & 12.3 \\
Oral function & 3.1 & 3.1 & 2.0 & 4.5 & 3.11 \\
Psychosocial impact & 7.0 & 6.0 & 4.4 & 10.3 & 6.5 \\
Orofacial pain & 11.9 & 9.1 & 7.7 & 7.2 & 10.1 \\
Appearance & 5.3 & 4.2 & 3.7 & 1.7 & 4.7 \\
DT & 3.5 & 3.8 & 2.2 & 3.2 & 3.5 \\
\hline
\end{tabular}

Table 4 Distribution of clinical severity counts at different visits

\begin{tabular}{|c|c|c|}
\hline Visit & CSI & Number of patients \\
\hline \multirow[t]{5}{*}{1} & 1 & 14 \\
\hline & 2 & 11 \\
\hline & 3 & 9 \\
\hline & 4 & 14 \\
\hline & 5 & 1 \\
\hline \multirow[t]{5}{*}{2} & 0 & 4 \\
\hline & 1 & 15 \\
\hline & 2 & 14 \\
\hline & 3 & 8 \\
\hline & 4 & 4 \\
\hline \multirow[t]{5}{*}{3} & 0 & 1 \\
\hline & 1 & 5 \\
\hline & 2 & 7 \\
\hline & 3 & 2 \\
\hline & 4 & 1 \\
\hline \multirow[t]{4}{*}{4} & 0 & 1 \\
\hline & 1 & 3 \\
\hline & 2 & 1 \\
\hline & 3 & 2 \\
\hline
\end{tabular}

\section{OHIP}

The clinical severity index (CSI) influenced the OHIP-G summary score, especially the dimensions "physical pain," "physical disability," "functional limitation," "psychological disability," "social disability," "handicap," "psychological discomfort," "orofacial pain," "oral function," "psychosocial impact," and "appearance." The worse the clinical presentation is, the higher the impact on perceived daily quality of life (Table 5).

\section{Considering the influence of different treatment options on OHIP (Table 5)}

Hyaluronic acid (Gengigel®) had a significant influence on OHIP improvement, subscore "physical pain," "psychological discomfort," "physical disability," "psychological disability, dimension," "psychosocial impact, dimension," "orofacial pain," and "appearance."

Topical corticosteroids had a significant negative impact on OHIP-G, "functional limitation," "psychological disability," "physical disability," "psychological discomfort," "physical pain," "DT," and "psychosocial impact."

Systemic corticosteroids had a negative impact on OHIPG, subscores "handicap," "physical disability," "oral function," and "functional limitation."

The photodynamic therapy had a significant influence on the perceived worsening of "oral function" $(\mathrm{t}-2.1, P=0.04)$. 
Table 5 Multiple regression analysis of significant independent variables on perceived VAS, CSI, and OHIP; CSI, clinical severity score; $H A$, hyaluronic acid; $T C$, topical triamcinolone; $S C$, systemic corticosteroids

\begin{tabular}{|c|c|c|c|c|}
\hline \multicolumn{5}{|l|}{ VAS } \\
\hline Predictor & $\Delta R^{2}$ & $\beta$ & $P$ & $T$ \\
\hline Gender & 0.12 & -.34 & 0.016 & -2.509 \\
\hline \multicolumn{5}{|l|}{ CSI } \\
\hline Predictor & $\Delta R^{2}$ & $\beta$ & $P$ & $T$ \\
\hline Age & 0.14 & -.30 & 0.022 & -2.05 \\
\hline Missing teeth & 0.14 & -.50 & 0.007 & -3.55 \\
\hline "Extraversion" & 0.14 & -.41 & 0.006 & -2.93 \\
\hline \multicolumn{5}{|l|}{ OHIP-G } \\
\hline Predictor & $\Delta R^{2}$ & $\beta$ & $P$ & $T$ \\
\hline CSI & 0.40 & .40 & 0.000 & 4.6 \\
\hline HA & 0.40 & -.29 & 0.007 & -2.7 \\
\hline $\mathrm{TC}$ & 0.40 & .32 & 0.004 & 3 \\
\hline "Conscientiousness" & 0.40 & -.22 & 0.03 & -2.1 \\
\hline \multicolumn{5}{|l|}{ Physical pain } \\
\hline Predictor & $\Delta R^{2}$ & $\beta$ & $P$ & $T$ \\
\hline CSI & 0.35 & .43 & 0.000 & 4.8 \\
\hline HA & 0.35 & -.30 & 0.008 & -2.7 \\
\hline $\mathrm{TC}$ & 0.35 & .26 & 0.02 & 2.3 \\
\hline \multicolumn{5}{|l|}{ Physical disability } \\
\hline Predictor & $\Delta R^{2}$ & $\beta$ & $P$ & $T$ \\
\hline CSI & 0.42 & .42 & 0.000 & 4.9 \\
\hline HA & 0.42 & -.23 & 0.03 & -2.2 \\
\hline $\mathrm{TC}$ & 0.42 & .32 & 0.003 & 3.1 \\
\hline $\mathrm{SC}$ & 0.42 & .20 & 0.02 & 2.3 \\
\hline "Conscientiousness" & 0.42 & -.30 & 0.003 & -3 \\
\hline \multicolumn{5}{|l|}{ Functional limitation } \\
\hline Predictor & $\Delta R^{2}$ & $\beta$ & $P$ & $T$ \\
\hline CSI & 0.33 & .35 & 0.000 & 3.8 \\
\hline $\mathrm{TC}$ & 0.33 & .22 & 0.05 & 2 \\
\hline $\mathrm{SC}$ & 0.33 & .21 & 0.03 & 2.2 \\
\hline \multicolumn{5}{|l|}{ Psychological disability } \\
\hline Predictor & $\Delta R^{2}$ & $\beta$ & $P$ & $T$ \\
\hline CSI & 0.35 & .30 & 0.001 & 3.4 \\
\hline HA & 0.35 & -.23 & 0.04 & -2.1 \\
\hline $\mathrm{TC}$ & 0.35 & .26 & 0.02 & 2.4 \\
\hline \multicolumn{5}{|l|}{ Social disability } \\
\hline Predictor & $\Delta R^{2}$ & $\beta$ & $P$ & $T$ \\
\hline CSI & 0.28 & .20 & 0.04 & 2.1 \\
\hline "Conscientiousness" & 0.28 & -.29 & 0.01 & -2.6 \\
\hline \multicolumn{5}{|l|}{ Handicap } \\
\hline Predictor & $\Delta R^{2}$ & $\beta$ & $P$ & $T$ \\
\hline CSI & 0.36 & .21 & 0.02 & 2.4 \\
\hline $\mathrm{SC}$ & 0.36 & .23 & 0.01 & 2.5 \\
\hline "Conscientiousness" & & & 0.004 & -3 \\
\hline \multicolumn{5}{|l|}{ Psychological discomfort } \\
\hline Predictor & $\Delta R^{2}$ & $\beta$ & $P$ & $T$ \\
\hline CSI & 0.35 & .34 & 0.000 & 3.8 \\
\hline HA & 0.35 & -.31 & 0.006 & -2.8 \\
\hline $\mathrm{TC}$ & 0.35 & .27 & 0.02 & 2.5 \\
\hline \multicolumn{5}{|l|}{ Orofacial pain } \\
\hline Predictor & $\Delta R^{2}$ & $\beta$ & $P$ & $T$ \\
\hline CSI & 0.35 & .44 & 0.000 & 4.9 \\
\hline Oral function & & & & \\
\hline Predictor & $\Delta R^{2}$ & $\beta$ & $P$ & $T$ \\
\hline CSI & 0.40 & .40 & 0.000 & 4.6 \\
\hline Missing teeth & 0.40 & .32 & 0.01 & 2.7 \\
\hline $\mathrm{SC}$ & 0.40 & .23 & 0.01 & 2.5 \\
\hline PDT & 0.40 & .19 & 0.04 & 2.1 \\
\hline Psychosocial impact & & & & \\
\hline Predictor & $\Delta R^{2}$ & $\beta$ & $P$ & $T$ \\
\hline CSI & 0.35 & .24 & 0.01 & 2.6 \\
\hline HA & 0.35 & -.28 & 0.01 & -2.5 \\
\hline $\mathrm{TC}$ & 0.35 & .27 & 0.02 & 2.5 \\
\hline "Conscientiousness" & 0.35 & -.25 & 0.02 & -2.4 \\
\hline Appearance & & & & \\
\hline Predictor & $\Delta R^{2}$ & $\beta$ & $P$ & $T$ \\
\hline CSI & 0.29 & .31 & 0.001 & 3.3 \\
\hline HA & 0.29 & -.26 & 0.03 & -2.3 \\
\hline DT & & & & \\
\hline Predictor & $\Delta R^{2}$ & $\beta$ & $p$ & $T$ \\
\hline $\mathrm{TC}$ & 0.22 & .25 & 0.04 & 2 \\
\hline
\end{tabular}




\section{NEO-FFI}

"Neuroticism" $1.6 \pm 0.5$, "extraversion" $2.3 \pm 0.5$, "openness" $2.4 \pm 0.4$, "agreeableness" $2.8 \pm 0.4$, and "conscientiousness" $2.9 \pm 0.5$.

The facet "conscientiousness" had a significant influence on OHIP-G, subscore improvement "social disability," "handicap," "physical disability," "DT," and "psychosocial impact" (Table 5).

A pronounced "extraversion" personality trait significantly influenced the clinical presentation assessed by CSI $(P=$ 0.006) during the course of treatment.

\section{Discussion}

A recent Cochrane review [21] quoted that the impact of pain on physical, emotional, and social functions required multidimensional qualitative tools and health-related quality of life instruments that are uncommonly used in OLP trials. Due to the chronic nature of OLP and the impact of this condition on quality of life, the use of patient-reported outcome measures in assessing the treatment of chronic oral mucosal diseases is of great importance. The influence of personality traits on oral health-related quality of life in patients suffering from the mucosal disease has been described previously [8]. Moreover, the present follow-up study showed a significant impact of personality traits on therapeutic outcomes in oral lichen planus patients. The facets "extraversion" and "conscientiousness" showed a significant influence on subjective as well as objective disease outcomes.

This chronic mucosal disease is mainly prevalent in a middle-aged female population where personality traits have been reported to be more stable after 30 years of age. The neuroticism extraversion openness five-factor inventory (NEO-FFI-R) questionnaire evaluates five personality traits (i.e., neuroticism, extraversion, openness, agreeableness, and conscientiousness) and consists of a psychological test with good structure and reliability. The trait "conscientiousness" had a significant influence on oral health-related quality of life in physical and psychosocial aspects. This trait is characterized by a tendency to be organized, show self-discipline, act dutifully, aim for achievement, and prefer planned rather than spontaneous behavior. Also, in recent literature, conscientiousness was positively related to treatment adherence, as this trait estimates motivation in goal-directed behavior. Regularity is required in topical treatment with immunomodulating agents. Therefore, the facet "conscientiousness" could influence higher treatment adherence. Furthermore, the caregiver's conscientiousness could have a significant influence on treatment outcome [22]. Self-efficacy mediated the effect of extraversion and conscientiousness on health-related quality of life [23-25].
The trait "extraversion" had a significant influence on the clinical severity of OLP patients. Extraversion is characterized by gratification from the external environment of the patient, linking interaction with others, being full of energy in the presence of others, and prefers human companionship to being on their own. Whether chronic disease may influence personality traits is a matter of debate. Nevertheless, clinically more severe cases may reduce the tendency to seek stimulation in the company of others and talkativeness. "Extraversion" seems to be protective in the psychosocial domain. This trait includes characteristics such as excitability, sociability, assertiveness, and high amounts of emotional expressiveness. Thus, an improvement in clinical severity may influence the sociability and talkativeness of patients. Vice versa, "extraversion" may modulate cortisol response to stress in chronic disease. It is known that OLP can appear and worsen during stressful events. Psychosocial factors such as personality traits are significantly associated with quality of life ratings. Such associations should be considered when the quality of life measurements are used and interpreted. Certain personality traits can lead to predicting positive health outcomes. In an elderly Japanese sample, conscientiousness, extraversion, and openness were related to a lower risk of mortality [26]. Individuals that score high on extraversion are prone to a more physically active lifestyle. In addition, extraversion negatively predicts perceived depression levels and potentially perceived stress. Hence, stress has a significant influence on OLP scores [27, 28], yet subjective outcome parameters were also influenced by an individual's characteristics such as male gender and higher age. Furthermore, different therapeutic options have diverse influences on the perceived quality of life. While corticosteroids seem to have a negative impact on well-being, hyaluronic acid has a significant beneficial effect on oral health-related quality of life.

A recent Cochrane review [21] found no evidence of a difference between topical steroids and placebo when measuring clinical resolution. The overall risk ratio of experiencing adverse effects caused by topical steroids was 1.48 compared with the placebo. Low-certainty evidence suggested that corticosteroids, particularly in topical formulations with adhesive bases, were effective in controlling the pain of OLP, though the findings were inconclusive for improving clinical presentation and uncertain about adverse effects.

We must also consider that many patients have prejudices again corticosteroids and patients as well as doctors have not been blinded to the prescribed treatments in the present study. This could have affected the regularity of the application. Furthermore, a strong weakness of the present study is the lack of a control group receiving a placebo or no treatment.

Topical steroids remain the first-line treatment for symptomatic OLP with proven efficacy and safety, but topical agents can probably not remain on the oral mucosa sufficient time to be 
absorbed. Therefore, the systemic or intralesional application is indicated when topical corticosteroid treatment is insufficient. Corticosteroid treatments nevertheless raise concerns in many patients due to the possible side effects [29]. One side effect of transient burning sensation with relapse has been reported in long-term corticosteroid and calcineurin inhibitor use, as seen especially for the seven patients at the fourth visit.

A recent study showed that $0.2 \%$ hyaluronic acid effectively improved the symptoms associated with OLP even after cessation of treatment. Hyaluronic acid is an effective substitute for topical corticosteroid with similar results. Moreover, in severely painful OLP, $0.2 \%$ HA could be used in addition to other topical drugs, such as corticosteroids and calcineurin inhibitors, to reduce the overall amount of immunosuppressant therapy used in a course of treatment [30].

Additionally, topical treatments depend on the patient's compliance, which may influence results. As mentioned previously "conscientiousness" correlates with self-discipline and could influence compliance. The personality factors "conscientiousness" and "agreeableness" were presented as predictors of high treatment adherence in oncology, recently [31]. Results from a renal dialysis study indicated that "conscientiousness" is a five-factor trait significantly associated with adherence to the medication regimen [32]. Personality traits may be a predictor of treatment non-adherence. In an antibiotic use study, the facet "neuroticism" was identified as a negative predictor, and both "agreeableness" and "conscientiousness" were identified as positive predictors of adherence behavior [33]. Hence, as topical therapy options necessitate patients compliance, compliance independent therapy approaches such as intralesional steroid application might be a better option in patients with a low "conscientiousness."

Concluding, "conscientiousness" and "extraversion" have a significant influence on therapeutic outcomes in OLP patients mainly treated with different topical agents.

Assessment of personality factors may be helpful in predicting the patient's cooperation and may affect treatment. Therefore, it would be reasonable to assess personality traits, in order to be more aware of patients' expectations and their possible compliance with an offered treatment. This may avoid extra time and effort. Psychological facets play a role in OLP management and explain the impacts on daily living and patients' satisfaction.

Funding Open access funding provided by Medical University of Vienna. The work was supported by the University Clinic of Dentistry of Vienna; no additional funding was received.

\section{Compliance with ethical standards}

Conflict of interest All authors declare that they have no conflict of interest.
Ethical approval All procedures performed in this study were in accordance with the ethical standards of the institutional research committee and with the 1964 Helsinki declaration and its later amendments.

Informed consent Informed consent was obtained from all individual participants included in the study.

Open Access This article is licensed under a Creative Commons Attribution 4.0 International License, which permits use, sharing, adaptation, distribution and reproduction in any medium or format, as long as you give appropriate credit to the original author(s) and the source, provide a link to the Creative Commons licence, and indicate if changes were made. The images or other third party material in this article are included in the article's Creative Commons licence, unless indicated otherwise in a credit line to the material. If material is not included in the article's Creative Commons licence and your intended use is not permitted by statutory regulation or exceeds the permitted use, you will need to obtain permission directly from the copyright holder. To view a copy of this licence, visit http://creativecommons.org/licenses/by/4.0/.

\section{References}

1. Zuo W, Li X, Chen Y, Peng H (2012) Oral health-related quality of life in patients with oral lichen planus. Hua Xi Kou Qiang Yi Xue Za Zhi 30:40-44

2. Lopez-Jornet P, Camacho-Alonso F (2010) Quality of life in patients with oral lichen planus. J Eval Clin Pract 16:111-113. https:// doi.org/10.1111/j.1365-2753.2009.01124.x

3. Lodi G, Carrozzo M, Furness S, Thongprasom K (2012) Interventions for treating oral lichen planus. Br J Dermatol. https://doi.org/10.1111/j.1365-2133.2012.10821.x

4. Lopez-Jornet P, Camacho-Alonso F, Salazar-Sanchez N (2010) Topical tacrolimus and pimecrolimus in the treatment of oral lichen planus: an update. J Oral Pathol Med 39:201-205. https://doi.org/ 10.1111/j.1600-0714.2009.00830.x

5. Thongprasom K, Carrozzo M, Furness S, Lodi G (2011) Interventions for treating oral lichen planus. Cochrane Database Syst Rev:CD001168. https://doi.org/10.1002/14651858. CD001168.pub2

6. van der Waal I (2009) Potentially malignant disorders of the oral and oropharyngeal mucosa; terminology, classification and present concepts of management. Oral Oncol 45:317-323. https://doi.org/ 10.1016/j.oraloncology.2008.05.016

7. Riordain RN, McCreary C (2012) Validity and reliability of a newly developed quality of life questionnaire for patients with chronic oral mucosal diseases. J Oral Pathol Med 40:604-609. https://doi. org/10.1111/j.1600-0714.2011.01021.x

8. Fadler A, Hartmann T, Bernhart T, Monshi B, Rappersberger K, Hof M, Dvorak G (2015) Effect of personality traits on the oral health-related quality of life in patients with oral mucosal disease. Clin Oral Investig 19:1245-1250. https://doi.org/10.1007/s00784014-1377-0

9. Al-Omiri MK, Karasneh J, Alhijawi MM, Zwiri AM, Scully C, Lynch E (2015) Recurrent aphthous stomatitis (RAS): a preliminary within-subject study of quality of life, oral health impacts and personality profiles. J Oral Pathol Med 44:278-283. https://doi.org/ 10.1111/jop. 12232

10. Karasneh J, Al-Omiri MK, Al-Hamad KQ, Al Quran FA (2009) Relationship between patients' oral health-related quality of life, satisfaction with dentition, and personality profiles. J Contemp Dent Pract 10:E049-E056 
11. Torres BL, Costa FO, Modena CM, Cota LO, Cortes MI, Seraidarian PI (2011) Association between personality traits and quality of life in patients treated with conventional mandibular dentures or implant-supported overdentures. J Oral Rehabil 38: 454-461. https://doi.org/10.1111/j.1365-2842.2010.02165.x

12. Penacoba C, Gonzalez MJ, Santos N, Romero M (2014) Psychosocial predictors of affect in adult patients undergoing orthodontic treatment. Eur J Orthod 36:93-98. https://doi.org/10. 1093/ejo/cjt007

13. Menassa M, de Grandmont P, Audy N, Durand R, Rompre P, Emami E (2016) Patients' expectations, satisfaction, and quality of life with immediate loading protocol. Clin Oral Implants Res 27:83-89. https://doi.org/10.1111/clr.12515

14. John MT, Patrick DL, Slade GD (2002) The German version of the Oral Health Impact Profile-translation and psychometric properties. Eur J Oral Sci 110:425-433

15. John MT, Micheelis W, Biffar R (2004) Reference values in oral health-related quality of life for the abbreviated version of the Oral Health Impact Profile. Schweiz Monatsschr Zahnmed 114:784-791

16. Salazar-Sanchez N, Lopez-Jornet P, Camacho-Alonso F, SanchezSiles M (2010) Efficacy of topical Aloe vera in patients with oral lichen planus: a randomized double-blind study. J Oral Pathol Med 39:735-740. https://doi.org/10.1111/j.1600-0714.2010.00947.x

17. Abu Hantash RO, Al-Omiri MK, Al-Wahadni AM (2006) Psychological impact on implant patients' oral health-related quality of life. Clin Oral Implants Res 17:116-123. https://doi.org/10. 1111/j.1600-0501.2005.01219.x

18. Thongprasom K, Chaimusig M, Korkij W, Sererat T, Luangjarmekorn L, Rojwattanasirivej S (2007) A randomizedcontrolled trial to compare topical cyclosporin with triamcinolone acetonide for the treatment of oral lichen planus. J Oral Pathol Med 36:142-146. https://doi.org/10.1111/j.1600-0714.2007.00510.x

19. Amin KA, Abdel Hameid H 2nd, Abd Elsttar AH (2010) Effect of food azo dyes tartrazine and carmoisine on biochemical parameters related to renal, hepatic function and oxidative stress biomarkers in young male rats. Food Chemi Toxicol 48:2994-2999. https://doi. org/10.1016/j.fct.2010.07.039

20. Thong ISK, Jensen MP, Miro J, Tan G (2018) The validity of pain intensity measures: what do the NRS, VAS, VRS, and FPS-R measure? Scand J Pain 18:99-107. https://doi.org/10.1515/sjpain-20180012

21. Lodi G, Manfredi M, Mercadante V, Murphy R, Carrozzo M (2020) Interventions for treating oral lichen planus: corticosteroid therapies. Cochrane Database Syst Rev 2:CD001168. https://doi. org/10.1002/14651858.CD001168.pub3

22. Ma X, Meng G, Tan Y, Liu X, Zhao Y, Yu J, Jin A, Zhao Y, Liu X (2018) Patient and family caregiver's neuroticism and conscientiousness personality in relation to quality of life of patient with Parkinson's disease: a cross-sectional study neuroticism and conscientiousness personality in relation to $\mathrm{QoL}$ of patient with PD. Front Neurol 9:754. https://doi.org/10.3389/fneur.2018.00754

23. Axelsson M, Brink E, Lundgren J, Lotvall J (2011) The influence of personality traits on reported adherence to medication in individuals with chronic disease: an epidemiological study in West Sweden. PLoS One 6:e18241. https://doi.org/10.1371/journal.pone.0018241

24. Axelsson M, Lotvall J, Cliffordson C, Lundgren J, Brink E (2013) Self-efficacy and adherence as mediating factors between personality traits and health-related quality of life. Qual Life Res Int J Qual Life Asp Treat Care Rehab 22:567-575. https://doi.org/10.1007/ s11136-012-0181-z

25. Axelsson M, Cliffordson C, Lundback B, Lotvall J (2013) The function of medication beliefs as mediators between personality traits and adherence behavior in people with asthma. Patient Prefer Adherence 7:1101-1109. https://doi.org/10.2147/PPA. S49725

26. Iwasa $\mathrm{H}$, Masui $\mathrm{Y}$, Gondo $\mathrm{Y}$, Inagaki $\mathrm{H}$, Kawaai $\mathrm{C}$, Suzuki $\mathrm{T}$ (2008) Personality and all-cause mortality among older adults dwelling in a Japanese community: a five-year population-based prospective cohort study. Am J Geriatr Psychiatry 16:399-405. https://doi.org/10.1097/JGP.0b013e3181662ac9

27. Mohamadi Hasel K, Besharat MA, Abdolhoseini A, Alaei Nasab S, Niknam S (2013) Relationships of personality factors to perceived stress, depression, and oral lichen planus severity. Int J Behav Med 20:286-292. https://doi.org/10.1007/s12529-012-9226-5

28. Cerqueira JDM, Moura JR, Arsati F, Lima-Arsati YBO, Bittencourt RA, Freitas VS (2018) Psychological disorders and oral lichen planus: a systematic review. J Investig Clin Dent 9:e12363. https://doi.org/10.1111/jicd.12363

29. Kurt MH, Kolsuz ME, Eren H (2019) Corticosteroid injection in treatment of persistent oral lichen planus: three cases. Dermatol Ther 32:e13015. https://doi.org/10.1111/dth.13015

30. Hashem AS, Issrani R, Elsayed TEE, Prabhu N (2019) Topical hyaluronic acid in the management of oral lichen planus: a comparative study. J Investig Clin Dent 10:e12385. https://doi.org/10. 1111/jicd.12385

31. Lima MP, Machado WL, Irigaray TQ (2018) Predictive factors of treatment adherence in cancer outpatients. Psycho-oncology 27: 2823-2828. https://doi.org/10.1002/pon.4897

32. Christensen AJ, Smith TW (1995) Personality and patient adherence: correlates of the five-factor model in renal dialysis. J Behav Med 18(3):305-313. https://doi.org/10.1007/BF01857875

33. Axelsson M (2013) Report on personality and adherence to antibiotic therapy: a population-based study. BMC Psychol 1(1):24. https://doi.org/10.1186/2050-7283-1-24

Publisher's note Springer Nature remains neutral with regard to jurisdictional claims in published maps and institutional affiliations. 